\title{
Hard to Know or Hard to Say? Developing Explicit Grammar Knowledge Among Primary Student Teachers
}

\author{
Huw Bell, Manchester Metropolitan University \\ Steph Ainsworth, Manchester Metropolitan University
}

\section{Introduction}

In this chapter we provide a critical and conceptual analysis of the challenges of teaching and learning first language grammatical knowledge in initial teacher education in England, based on an exploratory project aimed at helping trainee teachers with little formal linguistic education gain adequate knowledge of grammatical terminology. Beyond the Anglophone world, this may not seem problematic: 'most countries in Europe ... see grammar instruction as an important part of their school curriculum; and the same is true of previous European colonies such as Brazil' (Hudson 2016: 289). However, between around 1960 and 2000 learning about formal grammar was largely absent from schools in England and in much of the English-speaking world (Hudson \& Walmsley 2005), so many British teachers lack knowledge about grammar (KAG). Recent changes to the English primary curriculum mean teachers do now need some declarative knowledge of grammar terminology. In this chapter

\section{How to cite this book chapter:}

Bell, H. and Ainsworth, S. 2019. Hard to Know or Hard to Say? Developing Explicit Grammar Knowledge among Primary Student Teachers. In: Wright, C., Harvey, L. and Simpson, J. (eds.) Voices and Practices in Applied Linguistics: Diversifying a Discipline, pp. 195-210. York: White Rose University Press. DOI: https://doi. org/10.22599/BAAL1.1. Licence: CC BY-NC 4.0 
we describe our attempts to help our student teachers learn grammatical terminology, using an innovative pedagogy based on investigative learning, conceptual understanding and dialogic investigation, focused around carefully designed exemplars. Subsequent sections contribute to wider debates about the inadequacies of current accounts of what grammatical knowledge is and how it may be assessed in educational contexts, the limitations of terminology-driven teaching methods and the potential for applied linguistics to further inform the development of knowledge about grammar in schools.

\section{Background}

The English National Curriculum (DfE 2013a) includes a substantial list of metalinguistic terms that children aged five to 11 must learn, including many grammar terms. These terms are unattached to any particular theoretical perspective such as Systemic Functional linguistics (cp. Derewianka 2012) and might fairly be described as 'traditional' - most of them would be recognisable from 19thcentury textbooks. For many of our primary teacher trainees, however, they represent a source of considerable difficulty. Children's knowledge of grammar terms is examined in mandatory tests in the final year of primary schools in England, and the results form part of assessment of school performance; there is therefore a considerable amount at stake for children, teachers and schools.

A small body of research examines KAG among pre-service teachers. The findings from the UK vary somewhat but most are problematic: Chandler, Robinson and Noyes found 'partial gaps [in knowledge]' (1988: 161); Myhill (2000) reported significant misunderstandings and conceptual confusion; Cajkler and Hislam described 'misconceptions ... due to over-dependence on simple absolute definitions and a failure to appreciate functional shift' (2002: 175); Sangster, Anderson and O'Hara found levels of knowledge lower than levels of confidence (2013: 310). Work elsewhere echoes these findings: Harper and Rennie found Australian trainee teachers' KAG 'was fragmented and lacked depth' (2008: 22), and Jeurissen's 2012 report from New Zealand concurred. Williamson and Hardman concluded that 'a substantial amount of work' (1995: 123) was needed, and there is little to suggest that this has changed.

Our project is a small-scale attempt to directly inform initial teacher training using applied linguistic knowledge: specifically, we wanted to help our student teachers by supplementing their programme with a series of voluntary classes about grammar. In this chapter we report our experience of delivering these classes, and of using self-authored tests to assess participants' grammar knowledge before and after each course. Because the three occurrences were so different, we are unable to present precisely comparable quantitative data about learning and therefore cannot directly say which method is more effective. Instead we use elements of quantitative and qualitative data collected over two years to broadly interpret student teachers' experience of the courses and our 
experience of teaching them, to interrogate the critical and conceptual issues and better understand the challenge inherent in learning about grammar and to outline a possible pedagogy designed to support investigative learning.

We draw on our interpretations to develop a series of claims about the types of teaching and learning that we think can have a powerful impact on student teachers' understanding of grammar; the scope of terminological knowledge that teachers need; the broader relationship between analytic confidence and terminological knowledge; inadequacies of current accounts of what grammatical knowledge is; and the difficulties of assessing it. We finish by speculating on potential ways that applied linguistics might further inform the development of KAG in schools.

\section{Overview of the three courses}

In autumn 2016, spring 2017 and autumn 2017 we delivered three versions of a grammar course to different groups of student teachers (henceforth Cohorts 1, 2 and 3); these were roughly similar in size, with each cohort having 80-100 students. The three versions were broadly similar in certain respects. All participants were enrolled on the three-year BA Primary Education. Attendance at the classes was optional, and classes were delivered during a single term in an irregularly spaced pattern as timetable and school placement commitments allowed. The classes focused on key grammar terms from the National Curriculum (DfE 2013a) together with a small number which need not be taught to children but which we thought useful, and we placed a high priority on ensuring that all cohorts would become aware of the relationship between form and function in grammatical analysis. Each cohort was tested before and after the courses, and we also assessed participants' confidence in their knowledge. Most of the terminology taught remained consistent across cohorts (Table 5):

Table 5: terminology taught to all cohorts.

\begin{tabular}{|lll|}
\hline 1. Active verb form & 11. Main clause & 21. Present tense \\
2. Adjective & 12. Modal verb & 22. Pronoun \\
3. Adverb & 13. Noun & 23. Relative clause \\
4. Adverbial & 14. Noun phrase & 24. Relative pronoun \\
5. Auxiliary verb (primary) & 15. Object & 25. Subject \\
6. Clause & 16. Passive verb form & 26. Subjunctive \\
7. Complement & 17. Past tense & 27. Subordinate clause \\
8. Conjunction & 18. Possessive & 28. Subordinating \\
9. Coordinating & pronoun & conjunction \\
conjunction & 19. Preposition & 29. Verb \\
10. Determiner & 20. Preposition phrase* & 30. Verb phrase \\
\hline
\end{tabular}

* terms not included in the list of terminology for pupils in the NC. 
All students in each year group completed a test of grammar knowledge; students who attended the voluntary classes were a small proportion of those tested (between 10 and 50 participants). To obtain further insight into perceptions of the lessons, the test and the purposes and value of teaching grammar, small group interviews were held at the end of each course.

Overall, then, there were substantial similarities between the three iterations. There were also differences. Some of these were down to factors such as timetabling over which we had little control; this led to variation in the total length of the course, with the number of two-hour classes available varying between five and eight. In addition, Cohorts 1 and 3 were second-year students, and Cohort 2 were final years.

The ordering of items taught also varied. For Cohorts 1 and 2, content was arranged in a broadly analytic pattern from small to large: we taught word classes first, as we thought most students would have met them before, then phrases, clause elements and so on. For Cohort 3 we reversed this, starting with higher-ranked, more powerfully explanatory concepts.

We also made significant changes for Cohort 3 in both the test used and our approach to delivering the sessions. We discuss our test design in detail elsewhere (Bell \& Ainsworth, under review); however, we use the lessons learned from testing to inform some of the discussion here. We start by outlining our original teaching model, and then explain the changes to how and why it evolved.

\section{Teaching grammar: An evolution}

Classes in Cohorts 1 and 2 were designed largely around a traditional transmission model of teaching and were led mostly by the first author. Each session typically focused on 4-6 items of grammatical terminology and started with teacher input followed by practice activities, discussion and questions. These classes were broadly linear and progressive: each class built on the previous one and assumed that participants' knowledge grew incrementally.

\section{Cohort 1 lesson extract}

The lesson extract described here was the start of a session on phrases, based on input followed by practice activities. It depended for its success on students having mastered material from earlier lessons.

The session started with the whole group focused on a simple sentence with the subject underlined. Students were invited to add words to the subject in any way they wanted and in this way gradually expand the noun phrase:

The dog barked. $\rightarrow$ The old dog barked. $\rightarrow$ The old dog in the yard barked. 
The teacher then introduced the term noun phrase and explained certain principles associated with it: that a noun phrase frequently occurs in subject or object position; that it can be one word or many; that the obligatory element is a noun as the head; that pre- or post-modifiers can be present, such as determiners, adjectives and preposition phrases. The teacher also introduced the basic pronoun substitution test for a noun phrase. Students then used a variety of practice activities to support and expand their learning.

This teacher-led, transmissive approach allowed us to best fit the material to the time available in a coherent and logical order. The preliminary test results indicated that many students were familiar with major word classes, so we started with those to build on what was at least partially known, moving on later to less familiar terms.

However, our approach led to a number of problems. Introducing the terminology at the start of the activity meant many students had to start with something they did not understand rather than something they did. A terminology-first approach may sometimes be useful or even essential, but we found starting with the term entailed a multiplying effect, often forcing us to explain the new term using more new terms: the result confused and sometimes overwhelmed students.

The approach also seemed to suggest that the terminology itself was the important thing, rather than any use to which it might be put. It appeared dry and difficult: one student reported that although she usually enjoyed 'learning stuff for the sake of knowing ... grammar feels so academic that it's not a fun thing to learn. [I]t's quite difficult, it's not as interesting.'

Finally, there was a cost in terms of student affect: many students remained engaged until the end, but many found the material hard to master and retain. One Cohort 1 student noted that 'When we did the past tense, the perfect verbs ... that was a bad period. I was just like, what is going on?!' Several students appeared stressed by the learning load and the pace of the classes. We also found the classes difficult to manage and exhausting to deliver: with more than five to 10 students in the room, it became very hard to answer questions in a way which satisfied the questioner without distracting or confusing others.

Cohort 2 followed Cohort 1 closely, so we were unable to make substantial changes to content, but we did try to reduce the amount of teacher talk in favour of discussion between student participants. Overall, though, after Cohort 2 our impression remained that the transmission teaching model was ineffective.

In the six months between Cohorts 2 and 3, we analysed participants' reflections on their learning and considered alternative approaches. Our aims were to increase interest and engagement, and allow deeper, more beneficial learning. We thought one way to achieve this might be to allow students to use their procedural knowledge of English (Ryle 1949) to explore grammar. Procedural knowledge can be described as the ability to do something and can be contrasted with declarative knowledge, which is the ability to consciously 
reflect on our ability; an example might be the ability to balance and walk upright, which most people can do while quite unable to explain how they do it. We decided to avoid introducing any terminology until concepts had been thoroughly explored using the procedural knowledge that students brought to the class.

Rather than follow the transmissive teaching model used for Cohorts 1 and 2, therefore, the learning in autumn 2017 was designed to be inductive, exploratory and investigative. We placed particular emphasis on creating a need for terminology by first allowing students to develop conceptual understanding by dialogic investigation and analysis, and by not introducing any terms until this was well under way. Terminology was then used to anchor and formalise the hypotheses that students had created through shared, discursive analysis of the materials. The extract below illustrates this.

\section{Cohort 3 lesson extract}

This activity allowed students to develop conceptual understanding of concepts associated with noun phrase. It occurred at the start of the class, before any other input, and was presented as an exploratory puzzle rather than an exercise in knowledge of linguistic terminology.

\begin{tabular}{|l|l|}
\hline \multicolumn{2}{|l|}{ Activity A Compare the pairs of sentences below. How does it work? } \\
\hline 1. This well-matured goat's cheese is delicious. & {$[\mathrm{IT}]$ is delicious. } \\
\hline 2. Mr Jones and Mrs Mackay were good friends. & [THEY] were good friends. \\
\hline 3. I have eaten the chicken pie. & I have eaten [IT]. \\
\hline 4. This year more than 300 villagers have left. & This year [THEY] have left. \\
\hline 5. Most of these fish are captured while young. & [THEY] are captured while young. \\
\hline
\end{tabular}

Students worked in self-selected small groups to discuss the relationship between pairs of sentences, and within reason they were allowed as much time as they needed. The question - 'how does it work?' - was deliberately vague so that student explorations were not constrained by our instructions, yet interestingly we were never asked 'how does what work?' The activity purposefully avoids grammatical terminology. The task at first appeared to be relatively simple but typically took longer than anticipated. There was no clear end point, no absolutely right or wrong answer and no obvious method: students determined these for themselves.

This dialogic, discursive stage between students was followed by further discussion and questions both between students and with the teacher, but still no terminology was introduced. This initial activity was followed by a series of activities in a similar vein, such as this: 


\begin{tabular}{|l|l|}
\hline \begin{tabular}{l} 
Activity B Underline all the words in the sentence on the left which could be replaced \\
with the single word on the right. How do you know how to do this? \\
\hline The bloodiest war in European history lasted for four years.
\end{tabular} & IT \\
\hline You've got the wrong end of the rope. & IT \\
\hline I'm not sure the youngest students in Y5 will cope well with this. & THEY \\
\hline I'd like a tall skinny cappuccino as well. & ONE \\
\hline
\end{tabular}

Some terminology was by necessity introduced slowly as the lesson progressed. The precise terms depended on the lesson aims and the students' progress on the day, but in the lesson from which these example activities are drawn the terms would have included phrase, noun phrase, preposition phrase and head. Two hours spent worrying away at four or five terms may seem like slow progress, but much of the learning was conceptual rather than terminological. At the end of the full session, which comprised some 10-12 activities, students had at least partially uncovered for themselves the broad structural and functional parameters of noun phrase and preposition phrase, a key substitution test for noun phrases, and the nested relationship between preposition and noun phrases.

Two critical elements common to Cohort 3 activities was their almost total dependence on the students' procedural knowledge - their knowledge of how English works - and the generic appeal of a language puzzle. Our impression of the resulting learner activity was that, while it generated a similar number of questions overall, they were of a different type. In Cohorts 1 and 2, questions tended to refer back to terminology (e.g., 'what's the difference between defining and non-defining clauses again?'). Questions in Cohort 3, on the other hand, were rarely about terminology as such but were about the ways in which students were starting to view patterns as they formed hypotheses of their own: the later introduction of the terminology therefore answered a need rather than creating one.

Examples of this kind of alert, engaged thinking can be seen in student talk during activity B above. Students questioned each other ('Is it "you've got it"? Oh no, it's "you've got the wrong end of it" [Q2]), demanded a rationale from their partners ('How do you know it [the answer] isn't "the youngest students"? [Q3]) and used evidence to check their own hypotheses ("I'd like a one" doesn't make sense!' [Q4]).

We found that, as the lesson progressed, the sense of apprehension about lacking knowledge was slowly replaced by a sense of confidence and achievement. Cohort 3 students appeared to enjoy doing the activities - that is, discovering things about language structure - far more than earlier cohorts, as our field notes after the first session show:

We were concerned prior to the session that the students might not respond well to the activities - they might think why are we doing this - we 
know this already, but they were engaged and intrigued. You got the sense that the activities were making them think about things in a different way. Engagement levels were high throughout the activities. Seemed lower during transmissive [lessons] - some students were fidgety even though it was clear and relatively short.

In the sections that follow, we explore in more detail our hypotheses about how this change came about.

\section{Investigative learning leads to greater engagement}

Cohort 3 students reported being 'constantly engaged' during the activities, and they mostly attributed this to the investigative nature of the learning. The inquiry-based activities encouraged students to construct their own hypotheses about the language structures in front of them rather than passively absorbing taught knowledge. Because no student attended the grammar course twice, there is no direct evidence that any student preferred one delivery mode over another; however, many Cohort 3 students had experienced more traditional forms of learning through books and online materials during their placements and were therefore able to compare our approach with that found elsewhere. Their reflections on this experience provide interesting insights about the limitations of passively absorbing grammar knowledge, such as listening to a lecture or reading a grammar text. One Cohort 3 student noted that, when revising the sessions by looking over his notes, he was 'trying to relate back to the tasks ... rather than that description [of a term] written in a sentence.' He suggested that without the investigative problem focus of the sessions he would have found it hard to absorb or retain the concepts because he would have 'no activity ... or experience to relate it to.' The idea that inquiry-based learning is more effective than transmissive approaches where pupils are passive receptacles of knowledge is of course not new (e.g., Bruner 1961; see Freeman et al. 2014 for a review); however, the issue of exactly how and when this problembased learning should take place and the potential to integrate this with more formally taught input remains a matter of debate (Dobber, Zwart, Tanis \& van Oers 2017; Lazonder \& Harmsen 2016).

\section{Terminology last is better than terminology first}

We have already mentioned the importance of the deliberate omission of grammar terminology from Cohort 3 activities until conceptual groundwork was laid: we introduced terminology only after the activity had been completed and students had been provided with the opportunity to discuss and make conjectures about the language structures in front of them. Doing this seemed to 
enhance rather than limit their learning. As noted, some Cohort 1 and 2 students reported finding grammar terminology to be off-putting and a barrier to learning. In contrast, when Cohort 3 students were provided with the opportunities to experiment with the language before being asked to apply formal linguistic labels to it, they were engaged and inquisitive. One noted that 'we learnt how to identify something without knowing what it was [and] we really liked that.' A second explicitly referred to the desire to solve the mystery: 'I think the mystery's there, so you want to know what it is.'

It seemed to us that the central weakness of starting with terminology and building towards conceptual knowledge was that it failed to build on students' procedural knowledge of language. At least one Cohort 3 student appeared to confirm this: 'we kind of already know what verbs are. [B] ecause we did the activity first, and it wasn't actually entitled "verbs" until afterwards, we were starting to piece the gaps together.'

\section{Errors are valuable in hypothesis formation}

A further aspect of Cohort 3 pedagogy which seemed to have a significant impact on students' experiences of learning grammar was the value of errors in hypothesis formation. When attempting investigative tasks, students generated numerous erroneous hypotheses, which they explored through discussion before rejecting them in favour of more refined propositions. It also gave them opportunities to consolidate their existing knowledge of other grammatical concepts as they grappled with their conjectures. One student summarised it thus: 'When you make a mistake, you remember it. You can see a pattern sometimes, and we'd be like "oh, it's a complement" or whatever it is and then you get that last one and you're like "mmm, that's just totally thrown us."

The idea of errorful learning appears to have been little explored within the broader education literature. An early paper by Glaser (1966) identifies errorful learning as one of two defining characteristics of discovery learning, the second being induction. While discovery learning invokes induction by providing examples of a more general case and allowing the learner to infer the governing rule for themselves, errorful learning is invoked through the adoption of a teaching sequence with minimal structure, which 'of necessity, allows the student to pursue blind alleys and find negative instances' (Glaser 1966: 5), leading to the inevitable presence of frequent error.

In other words, discovery learning involves learners finding out rules for themselves with minimum external guidance. The unstructured, open-ended nature of the learning inevitably involves a process of trial and error before the learner happens upon (if indeed they ever do) the rule. The activities which we found to be especially successful in our sessions were both errorful and inductive: students were asked to generate a rule which would describe each of the examples provided with no initial guidance from the tutor. The examples were 
chosen to be representative of at least some of the diversity within a particular grammatical category (e.g., complements with varying form: adjective, noun phrase) to support learners in developing a full understanding of the concept at hand, rather than developing an incomplete understanding based on prototypical exemplars (e.g., subordinate clauses that are clearly marked by a subordinating conjunction). This diversity of exemplars also added to the probability of learners generating incorrect hypotheses, as each subtype of exemplar provided a potential red herring in terms of classification.

\section{Assessing what student teachers know}

We have delayed discussing our approach to assessing what our students know about grammar primarily because this chapter is largely about teaching and because we deal with testing in detail in a separate paper (Bell \& Ainsworth, under review). But an overview of our test and the results obtained are also useful here.

We designed and refined our test over the three cohorts. In each case, the test only examined knowledge of the terms covered in the classes (Table 5), and the test was delivered twice - at the start to serve as a diagnostic guide and to inform the content of the classes and after the classes had finished. All versions of the test were essentially based on recognising contextualised examples of given terms, as in this example:

In the sentence below, underline one example of terms 1-3.

I might prefer the other one, but yours is quite nice too.

1. possessive pronoun

2. modal verb

3. coordinating conjunction

We do not have space to discuss the detail of our test design, and although it was clearly flawed in many respects we believe it to be at least no worse (if not significantly better) than those used elsewhere (e.g., Bloor 1986; Harper \& Rennie 2008; Sangster et al. 2013). Whatever its faults, we assume that the results reveal something about student knowledge, and pre-course test results appeared to confirm that there was a knowledge problem. For example, in the pre-course test, $67 \%$ of Cohort 2 students correctly identified noun, but only $29 \%$ could identify verb; adverbial was correctly identified by $19 \%$, noun phrase by $9 \%$, passive by $4 \%$ and object by $2 \%$. By any standards, these figures suggest serious weaknesses in students' knowledge of grammar terms, with a lot of variation between both students and terms. Similar results were also found for Cohorts 1 and 3.

Cohort 2 students' mean score pre-course was 52\% (SD 13); the post-course mean was $55 \%$ (SD 20); this difference is not significant $(\mathrm{t}(95)=0.91, \mathrm{p}=.36$ ). We were surprised to find that attenders did not improve their knowledge more 
than non-attenders: attenders $(\mathrm{n}=28)$ mean percentage difference from test 1 to test $2=5.41(\mathrm{SD}=22.32)$, non-attenders $(\mathrm{n}=68)$ mean percentage difference from test 1 to test $2=1.03(\mathrm{SD}=25.55)$ - a difference that was not significant $(\mathrm{t}(94)=0.79, \mathrm{p}=.43)$.

The test scores did not agree with our own perceptions about the progress and confidence of students who attended classes: we observed growing confidence using terminology, and we noted that students' questions became more relevant and more tightly focused. In particular, it was noticeable that the test results did not agree with the perceptions of those students who attended: attending students from all cohorts reported in focus groups that they felt their understanding had improved.

\section{Conclusion}

We frame this section as a series of exploratory questions, since neither the data generated from the courses and tests nor our reflections on our experience of teaching allow us to provide conclusive answers. We feel that the questions and our exploratory discussion are relevant not only to those who educate student teachers but in some cases also to those who teach children.

\section{What types of teaching and learning have the most powerful impact on student teachers' understanding?}

There seemed little doubt to us that the quality of learning among Cohort 3 students, and their affective responses, were markedly better than that of Cohorts 1 and 2. The fundamental difference is the exploratory, discursive, discovery learning which used what students already knew (their procedural knowledge) to access, support and frame what they did not (the terminology). A Cohort 1 student commented that 'at school we were just taught the top layer [of understanding], that's why we're struggling now.' This type of learning positions the teacher as expert guide and the students as expert users and demonstrates to students that the expertise required to learn the terminology is fundamentally already theirs.

This point raises a more complex issue, which is the broader relationship between analytic confidence and terminological knowledge. It was noticeable that the quality of students' engagement with the problem of understanding grammar was higher in Cohort 3. It seemed to us that, as in mathematics education (Pratt \& Berry 2007; Brousseau 2002), the ability to consider alternative interpretations of the same data, to apply intuitive and learned skills to novel problems and to use all the evidence available (with or without terminology) are more effective than the limited learning opportunities provided by more traditional approaches. 


\section{Which terms do teachers need to know?}

The National Curriculum requires teachers to teach some 25 terms (Bell 2014: 7 ), but this number is an inadequate guide to the learning required. Grammar terms are a 'network of technical concepts that help to define each other' (DfE 2013b: 1): for example, it is difficult to understand preposition without understanding something about noun. Some useful terms are missing: for example, complement is not taught to children, but it is quite difficult to discuss clause structure without it. It seems reasonable to expect teachers to know more than the children they teach, but time pressure in teacher education programmes make it difficult to provide a full grammatical education. We propose instead that student teachers should focus on developing depth. The weakness of coverage without depth was expressed neatly by a student: 'if you've just learnt the definition of [a term] you've literally got one way of telling [pupils] what it means.' The implication for us is that deep knowledge, acquired via discovery and discussion, can equip teachers with analytic skills that will enable them to make up for a lack of breadth.

We tried to teach around 30 terms, but experience suggests that fewer terms, thoroughly explored in the manner described above, might be a better starting point for teaching and for learning more, providing a stronger basis for understanding how grammar works and how it can be described. In future iterations of the course we intend to focus on the following:

- Subject, verb, object, complement, adverbial;

- Noun phrase, verb phrase, preposition phrase, adjective phrase, adverb phrase;

- Main clause, subordinate clause, conjunction, relative pronoun, sentence.

\section{What is grammatical knowledge, and (how) should it be assessed?}

At one level our test was adequate to its main purpose of identifying what students already knew about grammar. However, its reliability and validity must be called into question: either students learned virtually nothing during the classes (something neither we nor the students themselves would agree with) or the test was unable to tap into the kinds of insights students were developing. We presume that it would be possible technically to develop a test which did explore in detail exactly what takers knew, with sufficient subtlety to pick up incremental changes in knowledge, but we do not think it would be easy or even worthwhile.

It seems to us that, in our context, the requirements of any test should match the aims of the classes. If the aims of the learning are to memorise identification rules for or definitions of, for example, preposition, then it will be relatively straightforward to design a test to establish whether the taker has indeed 
memorised the rules. As we have seen, however, the aims of our classes (when they ultimately came into view over repeated iterations) were rather different. We have come to believe that the real aim of this type of grammatical 'instruction' should be to use existing procedural expertise to develop confidence in examining language in situ, to develop and test hypotheses about potential answers to questions which at a higher level may never be resolved. In other words, having declarative knowledge of grammar is not a simple matter of memorising definitions but instead an infinitely complex issue involving identification and analysis of problems inside a moving world of usage.

In this light, testing grammar is virtually the same as learning about it. Every analysis is a test. Using definition-based or exemplar-based tests of the 'underline an example of $\mathrm{X}$ ' variety simply reinforces the idea that the right answer, the destination, is more important than the journey; we do not believe this to be true. We struggled to create a grammar test that fulfils the intended task, but we can resolve this difficulty by acknowledging that the journey is greater than the destination and that in grammar one can be right in a bad way and wrong in a good one. If students are asked, for example, to identify a preposition in the following sentence, only the underlined answer is correct:

I wanted to get my next car from a proper garage.

It is clearly possible to get the right answer using simple knowledge of the fact that 'from is a preposition' and still know nothing about prepositions in general. This may well be what happens when children learn grammar terminology in schools; from our experience, it certainly tended to be what happened among some students in Cohort 1, where the transmission model encouraged a 'surface' approach to learning (Marton \& Säljö 1976).

The difficulties of assessing grammatical knowledge reflect a deeper underlying problem with our definition of what grammatical knowledge is - or, more precisely, what type of grammatical knowledge we expect teachers to have. It must be more than procedural knowledge - must, in other words, be declarative - but in what does this consist? We do not have space to fully consider this here, but the National Curriculum effectively conflates declarative grammatical knowledge with terminological knowledge. It seems to us that teaching about grammar is unlikely to move much beyond 'knowing terms' without a more detailed exploration of this issue.

One last point may be relevant. There is some overlap between the type of grammar teaching we have described here and that traditionally undertaken in classes for those learning English as a second language. For example, our transmission model of teaching resembles that used in a traditional approach to teaching L2 grammar, such as grammar translation, and our revised pedagogy has similarities to task-based learning. But the surface similarities hide a deeper difference. For adult learners of an L2, one of the main aims of second language instruction is in fact to develop precisely that procedural knowledge 
which our student teachers already have. For many L2 learners the hardest part of the journey is converting declarative knowledge (e.g., about the uses of various verb forms) into procedural knowledge (the ability to use the correct verb form quickly and accurately), whereas for our teachers the difficulty is effectively the reverse - moving beyond the unreflecting natural skill to a conscious analytic understanding.

\section{How can applied linguistics contribute to teacher education in grammar?}

Applied linguistic research has had a considerable impact on education policy, even if professional bodies (in the UK at least) sometimes feel like 'commentators without significant policy influence' (Mitchell \& Myers 2017: 17). With regards to one small area - the development of knowledge about grammar in student teachers - most teacher training providers undoubtedly do valuable work to develop student teachers' content and pedagogic knowledge of grammar (e.g., Dombey \& Briggs 2011). However, it is difficult to see how such work can have much impact at a policy level without at least a consistent and principled approach to working out what student teachers need to know and to developing a range of appropriate pedagogies for teaching them. Ways to share and build on such local work through professional bodies such as BAAL and the recently formed Linguistics and Knowledge about Language in Education Special Interest Group are helpful here, although we believe there is a strong case for still closer cooperation on a local scale between applied linguists and those with expertise in pedagogy, curriculum and teacher education. It is hard to affect policy without concerted action, especially in a landscape of teacher education which is 'more fragmented and diverse than ever before' (McNamara, Murray \& Phillips 2017: 5), and particularly in the era of 'what works' (EEF 2018). We would suggest that our questions above cannot be answered without cooperation and that until they are we are unlikely to see radical improvements in the way KAG is taught in primary schools.

\section{References}

Bell, H. 2014 The dead butler revisited: Grammatical accuracy and clarity in the English Primary Curriculum 2013-2014. Language and Education, 29(2): 140-152.

Bell, H. and Ainsworth, S. (under review) Difficulties assessing knowledge of grammatical terminology: Implications for teacher education and teaching.

Bloor, T. 1986 What do language students know about grammar? British Journal of Language Teaching, 24(3): 157-162. 
Brousseau, G. 2002 Theory of didactical situations in mathematics. Dordrecht: Kluwer.

Bruner, J. 1961 The act of discovery. Harvard Educational Review, 31(1): 21-32.

Cajkler, W. and Hislam, J. 2002 Trainee teachers' grammatical knowledge: The tension between public expectation and individual competence. Language Awareness, 11(3): 161-177.

Chandler, P., Robinson W.P. and Noyes, P. 1988 The level of linguistic knowledge and awareness amongst students training to be primary teachers. Language and Education, 2(3): 161-173.

Derewianka, B. 2012 Knowledge about language in the Australian curriculum: English. Australian Journal of Language and Literacy, 35(2): 127-146.

DfE 2013a English programmes of study: Key stages 1 and 2 National Curriculum in England. London: Department for Education.

DfE 2013b Glossary for the programmes of study for English (non-statutory). London: Department for Education.

Dobber, M., Zwart, R., Tanis, M. and van Oers, B. 2017 Literature review: The role of the teacher in inquiry-based education. Educational Research Review, 22: 194-214.

Dombey, H. and Briggs, J. 2011 Building knowledge about language into a primary teacher education course. In Ellis, S. and McCartney, E. (eds), Applied linguistics and primary school teaching. Cambridge: Cambridge University Press.

EEF 2018 Teaching and learning toolkit. London: Education Endowment Foundation.

Freeman, S., Eddy, S., McDonough, M., Smith, M., Okoroafor, N., Jordt, H. and Wenderotha, M. 2014 Active learning increases student performance in science, engineering, and mathematics. Psychological and Cognitive Sciences, 111(23): 8410-8415.

Glaser, R. 1966 Variables in discovery learning. Presentation. Pittsburgh, PA: Pittsburgh University Learning Research and Development Center.

Harper, H. and Rennie, J. 2008 'I had to go out and get myself a book on grammar': A study of pre-service teachers' knowledge about language. Australian Journal of Language and Literacy, 32(1): 22-37.

Hudson, R. 2016 Grammar instruction. In MacArthur, C., Graham, S. and Fitzgerald, J. (eds), Handbook of writing research. 2nd ed. New York: Guilford.

Hudson, R. and Walmsley, J. 2005 The English patient: English grammar and teaching in the twentieth century. Journal of Linguistics, 41: 593-622.

Jeurissen, M. 2012 'Perhaps I didn't really have as good a knowledge as I thought I had.' What do primary school teachers know and believe about grammar and grammar teaching? Australian Journal of Language and Literacy, 35(3): 301-316.

Lazonder, A.W. and Harmsen, R. 2016 Meta-analysis of inquiry-based learning: Effects of guidance. Review of Educational Research, 86(3), 681-718. 
Marton, F. and Säljö, R. 1976 On qualitative differences in learning. I-Outcome and process. British Journal of Educational Psychology, 46, 4-11.

McNamara, O., Murray, J. and Phillips, R. 2017 Policy and research evidence in the 'reform' of primary initial teacher education in England. Cambridge: Cambridge Primary Review Trust.

Myhill, D. 2000 Misconceptions and difficulties in the acquisition of metalinguistic knowledge. Language and Education, 14(3): 151-163.

Mitchell, R. and Myers. G. 2017 Notes on the history of the British Association for Applied Linguistics 1967-2017. British Association for Applied Linguistics.

Pratt, N. and Berry, J. 2007 'The joy of mathematics'. In Hayes, D. (ed.), Teaching and learning in the primary school. Exeter: Learning Matters.

Ryle, G. 1949 The concept of mind. London: Hutchinson.

Sangster, P., Anderson, C. and O'Hara, P. 2013 Perceived and actual levels of knowledge about language amongst primary and secondary student teachers: Do they know what they think they know? Language Awareness, 22(4): 293-319.

Williamson, J. and Hardman, F. 1995 Time for refilling the bath? A study of primary student-teachers' grammatical knowledge. Language and Education, 9(2): 117-134. 